\title{
Advantages and Disadvantages of Targeting the C-erbB Family of Receptors in Cancer Treatment: A Review
}

\section{Panagiotis Papanastasopoulos}

Imperial College, NHS Trust, Charing Cross Hospital, Fulham Palace Rd, London W6 8RF, UK

*Corresponding author: Panagiotis Papanastasopoulos, Imperia I College, NHS Trust, Charing Cross Hospital, Fulham Palace Rd, London W6 8RF, UK, Tel: +44 20 3311 1423; E-mail: PPapanastasopoulos@nhs.net

Received date: March 28, 2014; Accepted date: May 21, 2014; Publishing date: May 28, 2014

Copyright: (c) 2014 Papanastasopoulos P. This is an open-access article distributed under the terms of the Creative Commons Attribution License, which permits unrestricted use, distribution, and reproduction in any medium, provided the original author and source are credited.

\begin{abstract}
C-erbB (EGFR) signaling is well known to promote cancer invasiveness and metastasis. Several pharmacologic approaches have been used aiming to inhibit its activity, ie monoclonal antibodies, antibody-like molecules (peptidomimetics) and receptor tyrosine kinase inhibitors. Several C-erbB signaling 'inhibitors', such as Trastuzumab, Cetuximab, gefitinib, erlotinib and lapatinib are now widely used in clinical practice, having revolutionized the management of certain malignancies, such as HER-2 positive breast cancer. In this review, we present an overview of the mechanism of action, pharmacokinetic properties, mechanism of resistance as well as the relative cost of administration for each group of EGFR inhibitors separately.
\end{abstract}

Keywords: C-erbB; Signaling; Monoclonal antibodies; TKI; Peptidomimetics

\section{Introduction}

The C-erbB family of receptors consists of tyrosine kinase receptors (TKR) with a physiological role in cellular proliferation, survival and differentiation. The family consists of 4 members, also known as the epidermal growth factor receptors (EGFR): ErbB1 (HER1), ErbB2 (HER2 or Neu), ErbB3 (HER3), and ErbB4 (HER4) [1]. They are structurally related and consist of an extracellular ligand-binding domain, a trans membane domain, and a cytoplasmic domain with a catalytic kinase activity. ErbB1 is primarily activated by EGF and TFGa, whereas ErbB3 and ErbB4 are the receptors for the neuregulins. So far no ligand has been identified for HER2 [1].

As a general rule, ligand binding promotes the formation of homo and heterodimers between different receptors, which leads to the activation of the cytoplasmic domain kinase activity, resulting in transphosphorylation of the latter in tyrosine residues [1]. HER2 appears to be the preferred partner for the rest of EGFR [2]. The phosphorylated cytoplasmic domain functions as a docking site for downstream molecules with phosphotyrosine-binding domains, which mediate the signal through the activation of downstream molecular pathways: 1) the mitogen-activated protein kinase (MAPK), 2) the Akt/ phosphoinositide 3-kinase (PI3-kinase) and 3) the mammalian target of rapamycin (mTOR) pathway [1,3]. Ultimately, the signal will be transduced to the nucleus via secondary mediators, where specific up regulation and/ or down regulation of several gene groups, involved in cellular proliferation, survival, differentiation, angiogenesis and motility will take place [1]. Any dys regulation of the fine balance maintained between the cellular processes mentioned above can easily trigger malignant transformation to the cell.

EGFR are known to play a significant role in the pathophysiology of several cancer types in human. Gene amplifications and numerous mutations which may increase the transcription and stability of the receptors have been identified. As a consequence, an increased number of receptors are available each time on the cell surface, resulting in dimerization and activation of the kinase domain, without necessarily the presence of a ligand. A classic example is the overexpression of HER2 by $25 \%$ of invasive breast cancer cases, relating to poor prognosis. Other tumors where EGFR signaling is involved are non-small cell lung cancer and colorectal cancer [4-6].

Several therapeutic strategies are currently utilized to selectively target EGFR signaling in cancer cells; 1) monoclonal antibodies or antibody-like molecules (mab), 2) development of small molecules, tyrosine kinase inhibitors (TKI), 3) attachment of toxins to EGFR antibodies or ligands, 4) anti-sense therapies, 5) gene therapies.

\section{Monoclonal Antibodies (MAb)}

One of the first approaches to inactivate EGFR signaling was the development of monoclonal antibodies. EGFR-specific murinederived mab were found to substantially reduce the expression of the receptor on the membrane of cancer cells, reversing their malignant transformation [6]. Similarly, treatment with monoclonal antibodies inhibited the growth of tumors expressing EGFR in xenograft models [7]. Mab show a high affinity for the extracellular receptor domain, competitively preventing the binding of activating ligands. They are also known to induce receptor internalisation and degradation [7-9]. An antibody-dependent cellular cytotoxicity (ADCC), driven by natural killer cells and macrophages which bind to the mab-EGFR complex, was also identified [10].

Two of the main initial problems were to overcome the human antimouse antibody immune response which limited their activity in humans, and also their reduced affinity for the human homolog receptor. The solution was given with the development of chimeric (human-mouse) monoclonal antibodies, and later on, fully humanized mab.

Cetuximab is a chimeric mab targeting ErbB1, with a 10 -fold greater affinity compared to its physiological ligands [11]. It induces apoptosis via the up-regulation of p27Kip1, therefore arresting cancer cells in G1 phase [12]. There is also evidence that cetuximab sensitizes 
cancer cells to the cytotoxic effects of chemotherapy and radiotherapy; In chemotherapy-refractory xenograft models, combined treatment induced a more extensive tumour regression as opposed to chemotherapy alone [13]. Furthermore, cetuximab-treated cancer cells demonstrated an inhibition in their DNA repair mechanisms, increasing their sensitivity to radiation [12].

In clinical studies, cetuximab was found to have a half-life (t1/2) of 7 days [8], demonstrating a benefit in response rate and progression free survival [14]. In colorectal cancer, it is only effective in KRAS-wild type patients [15]. KRAS is a downstream mediator of EGFR signaling, and when mutated and constitutively activated, the MAPK-pathway activation is independent of the EGFR status [16]. Finally, the addition of Cetuximab to platinum-based chemotherapy and radiotherapy in recurrent/metastatic head and neck SCC patients demonstrated significant efficacy [17].

Panitumumab is a fully humanized mab which binds with greater affinity (compared to cetuximab) to $\mathrm{ErbB}_{1}$, causing no immunogenicity. In xenograft models, it achieved to completely eradicate tumours as monotherapy, as opposed to cetuximab $[7,18]$. In clinical trials of metastatic colorectal cancer, the combination of panitumumab and chemotherapy was found to confer a PFS advantage [19]. For both cetuximab and panitumumab, the main side effects consist of an acneiform rash, gastrointestinal toxicity and hypomagnesemia. They are intravenously administered on a 2-3 weekly basis, and the cost for eight weeks of treatment with cetuximab is approximately $\$ 30,000$ per patient.

In breast cancer, the recombinant humanized anti-HER2 mab, Trastuzumab, revolutionalized breast cancer management, with significant clinical response rates in the metastatic setting, and an important reduction in the recurrence rate when used adjuvantly [20]. Mechanisms of resistance to trastuzumab have been described, such as the loss of phosphatase and tensin homolog (PTEN), the presence of the ectodomain-missing p95her2/neu receptor and insulin-growth factor 1 overexpression [21-23]. Clinical trials investigating the combined use of Trastuzumab and Pertuzumab (blocking receptor dimerization) to maximize EGFR inhibition are on-going. Trastuzumab side effects consist of mainly allergic reactions and cardio toxicity, requiring close cardiac function monitoring. It is given intravenously on a 3-weekly basis. A full one-year course of Trastuzumab treatment costs approximately $\$ 70,000$ per patient.

\section{Antbody-like Molecules/Peptidomimetics}

Monoclonal antibodies face certain limitations, such as their size, preventing them from crossing the blood-brain barrier (BBB) where disease is often found, and also achieving rather low concentrations into solid tumors. Several laboratories have developed smaller molecules that usually consist of or resemble a specific part of the initial mab that is complementary to the targeted receptor. They can be potentially used to deliver drugs specifically to the cancer cells or prevent receptor dimerization. The main disadvantages are their low affinity, short half-life and their inability to induce ADCC. Such molecules are found in early experimental phases currently $[5,24]$.

\section{Receptor Tyrosine Kinase Inhibitors}

Small molecules functioning as tyrosine kinase inhibitors are used to block EGFR signaling. They bind to the hydrophobic pocket of the cytoplasmic ATP-binding domain of EGFR, with high specificity, resulting in inhibition of the downstream signaling pathways.
Reversible TKI compete with ATP for the binding site, whereas irreversible inhibitors alkylate a cysteine residue within the ATPpocket, causing a permanent inhibition [5,25]. Some TKI can also indirectly inhibit more than one of the EGFR family members, possibly via blocking receptor dimerization [26]. They are administered orally and their half-life is much shorter compared to mab (i.e., lapatinib t1/2: 24 hours). Finally they can pass through the $\mathrm{BBB}$ and have been incorporated in treatments for CNS metastatic disease [27].

\section{Reversible TKI}

Erlotinib and Gefitinib are selective inhibitors of HER1, whereas Lapatinib can inhibit both HER1 and HER2. All three TKI have been incorporated in the management of several tumors, primarily including breast and non-smal cell lung cancer (NSCLC), based on their efficacy from pre-clinical and clinical trials [27-29]. NSCLC patients bearing certain mutations, increasing the affinity of the receptor for TKI, were found to benefit more from erlotinib or gefitinib [30]. Similarly, lapatinib was found to be effective against the trastuzumab-resistant ectodomain-missing p95her2/neu receptor [23]. A percentage of NSCLC patients with progression after continuous treatment with Gefitinib, develop a single point mutation which increases ATP affinity for EGFR, therefore bypassing inhibition [31]. Resistance can also develop via the up-regulation of other existing pathways that cross-talk to EGFR signaling, and compensate for its lost activity (i.e., up-regulation of Met gene), as well as altered receptor internalization [32]. More surprisingly, there is evidence that despite continuous treatment with TKI, HER1 and HER2 blockage is not durable, and results in the overexpression of HER3 which is preferentially signaling via the PI3-kinase/Akt pathway, conferring resistance to TKI [33].

\section{Irreversible TKI}

Irreversible TKI were designed to overcome the problem of incomplete inhibition caused by the reversible group. They were also found to be effective against cancer cells bearing in sensitizing mutations to reversible TKI. As they permanently deactivate EGFR kinase activity, intermittent treatment may be feasible, reducing toxicity. Irreversible TKI inhibit all EGFR family members and are currently investigated within clinical trials $[5,8,34]$.

The main side effects from anti-EGFR TKI consist of fatigue, gastrointestinal toxicity, rash, cardio toxicity, impaired liver function tests, pneumonitis and infections. The cost of a year's treatment with Erlotinib and Lapatinib is approximately $£ 18,000$ and $£ 20,000$, respectively.

\section{Conclusions}

Various anti-EGFR agents are currently being used in current practice with promising efficacy, and overall limited toxicity compared to conventional chemotherapy. Increasing the affinity of designed drugs to EGFR, and modifying their chemical structure to achieve adequate and selective uptake by cancer cells can potentially reverse resistance. As resistance usually develops either through mutations/ up-regulation of downstream signaling molecules, or the compensatory activation of other existing signaling pathways, combined treatment with different classes of EGFR inhibitors or inhibitors of different pathways may provide a more successful approach. Concomitant targeting of downstream molecules, such as 
survivin or MAPK, integrating signals from different cellular pathways may increase treatment efficacy. Identifying in sensitizing ss mutations and designing molecules that specifically target them is another potential strategy. Finally, anti-sense treatments and gene therapies, even though currently in very early phase research, consist of approaches that may prove extremely useful tools in the future.

\section{References}

1. Casalini P, Iorio MV, Galmozzi E, Ménard S (2004) Role of HER receptors family in development and differentiation. J Cell Physiol 200: 343-350.

2. Graus-Porta D, Beerli RR, Daly JM, Hynes NE (1997) ErbB-2, the preferred heterodimerization partner of all ErbB receptors, is a mediator of lateral signaling. EMBO J 16: 1647-1655.

3. Klos KS, Wyszomierski SL, Sun M, Tan M, Zhou X, et al. (2006) ErbB2 increases vascular endothelial growth factor protein synthesis via activation of mammalian target of rapamycin/p70S6K leading to increased angiogenesis and spontaneous metastasis of human breast cancer cells. Cancer Res 66:2028-2037.

4. Hsieh AC, Moasser MM (2007) Targeting HER proteins in cancer therapy and the role of the non-target HER3. Br J Cancer 97: 453-457.

5. Zhang H, Berezov A, Wang Q, Zhang G, Drebin J, et al. (2007) ErbB receptors: from oncogenes to targeted cancer therapies. J Clin Invest 117: 2051-2058.

6. Weiner DB, Liu J, Cohen JA, Williams WV, Greene MI (1989) A point mutation in the neu oncogene mimics ligand induction of receptor aggregation. Nature 339: 230-231.

7. Yang XD, Jia XC, Corvalan JR, Wang P, Davis CG (2001) Development of ABX-EGF, a fully human anti-EGF receptor monoclonal antibody, for cancer therapy. Crit Rev Oncol Hematol 38: 17-23.

8. de Bono JS, Rowinsky EK (2002) The ErbB receptor family: a therapeutic target for cancer. Trends Mol Med 8: S19-26.

9. Baselga J (2001) The EGFR as a target for anticancer therapy--focus on cetuximab. Eur J Cancer 37 Suppl 4: S16-S22.

10. Lewis GD, Figari I, Fendly B, Wong WL, Carter P, et al. (1993) Differential responses of human tumor cell lines to anti-p185HER2 monoclonal antibodies. Cancer Immunol Immunother 37: 255-263.

11. Goldstein NI, Prewett M, Zuklys K, Rockwell P, Mendelsohn J (1995) Biological efficacy of a chimeric antibody to the epidermal growth factor receptor in a human tumor xenograft model. Clin Cancer Res 1: 1311-1318.

12. Huang SM, Bock JM, Harari PM (1999) Epidermal growth factor receptor blockade with $\mathrm{C} 225$ modulates proliferation, apoptosis, and radiosensitivity in squamous cell carcinomas of the head and neck. Cancer Res 59: 1935-1940.

13. Overholser JP, Prewett MC, Hooper AT, Waksal HW, Hicklin DJ (2000) Epidermal growth factor receptor blockade by antibody IMC-C225 inhibits growth of a human pancreatic carcinoma xenograft in nude mice. Cancer 89: 74-82.

14. Sobrero AF, Fehrenbacher L, Rivera F, Steinhauer EU and Prausova J, et al. (2007) Randomized phase III trial of cetuximab plus irinotecan versus irinotecan alone for metastatic colorectal cancer in 1298 patients who have failed prior oxaliplatin based therapy: the EPIC trial. [abstract]. In: American Association for Cancer Research Annual Meeting: Proceedings; 2007 Apr 14-18; Los Angeles, CA. Philadelphia (PA): AACR; 2007. Abstract nr LB-2.

15. Karapetis CS, Khambata-Ford S, Jonker DJ, O'Callaghan CJ, Tu D, et al. (2008) K-ras mutations and benefit from cetuximab in advanced colorectal cancer. N Engl J Med 359: 1757-1765.

16. Prenen H, Tejpar S, Van Cutsem E (2010) New strategies for treatment of KRAS mutant metastatic colorectal cancer. Clin Cancer Res 16: 2921-2926.
17. Reeves TD, Hill EG, Armeson KE, Gillespie MB (2011) Cetuximab therapy for head and neck squamous cell carcinoma: a systematic review of the data. Otolaryngol Head Neck Surg 144: 676-684.

18. Fan Z, Baselga J, Masui H, Mendelsohn J (1993) Antitumor effect of antiepidermal growth factor receptor monoclonal antibodies plus cisdiammined ichloroplatinum on well-established A431 cell xenografts. Cancer Res 53: 4637-4642.

19. Peeters M, Price TJ, Hotko YS, Cervantes-Ruiperez A, Ducreux M, et al. (2010) Randomized phase III study of panitumumab (pmab) with FOLFIRI versus FOLFIRI alone as second-line treatment (tx) in patients (pts) with metastatic colorectal cancer (mCRC): Patient-reported outcomes (PRO). Gastrointestinal Cancers Symposium, USA.

20. Romond EH, Perez EA, Bryant J, Suman VJ, Geyer CE Jr, et al. (2005) Trastuzumab plus adjuvant chemotherapy for operable HER2-positive breast cancer. N Engl J Med 353: 1673-1684.

21. Depowski PL, Rosenthal SI, Ross JS (2001) Loss of expression of the PTEN gene protein product is associated with poor outcome in breast cancer. Mod Pathol 14: 672-676.

22. Nahta R, Yuan LX, Zhang B, Kobayashi R, Esteva FJ. Insulin-like growth factor-I receptor/human epidermal growth factor receptor heterodimerization contributes to trastuzumab resistance of breast cancer cells. Cancer 65:11118-11128.

23. Scaltriti M, Rojo F, Ocaña A, Anido J, Guzman M, et al. (2007) Expression of p95HER2, a truncated form of the HER2 receptor, and response to anti-HER2 therapies in breast cancer. J Natl Cancer Inst 99: 628-638.

24. Berezov A, Zhang HT, Greene MI, Murali R (2001) Disabling erbB receptors with rationally designed exocyclic mimetics of antibodies: structure-function analysis. J Med Chem 44: 2565-2574.

25. Ward WH, Cook PN, Slater AM, Davies DH, Holdgate GA, et al. (1994) Epidermal growth factor receptor tyrosine kinase. Investigation of catalytic mechanism, structure-based searching and discovery of a potent inhibitor. Biochem Pharmacol 48: 659-666.

26. Moulder SL, Yakes FM, Muthuswamy SK, Bianco R, Simpson JF, et al. (2001) Epidermal growth factor receptor (HER1) tyrosine kinase inhibitor ZD1839 (Iressa) inhibits HER2/neu (erbB2)-overexpressing breast cancer cells in vitro and in vivo. Cancer Res 61: 8887-8895.

27. Oakman C, Pestrin M, Zafarana E, Cantisani E, Di Leo A (2010) Role of lapatinib in the first-line treatment of patients with metastatic breast cancer. Cancer Manag Res 2: 13-25.

28. Cappuzzo F, Ciuleanu T, Stelmakh L, Cicenas S, Szczésna A, et al. (2010) Erlotinib as maintenance treatment in advanced non-small-cell lung cancer: a multicentre, randomised, placebo-controlled phase 3 study. Lancet Oncol 11: 521-529.

29. Maemondo M, Inoue A, Kobayashi K, Sugawara S, Oizumi S, et al. (2010) Gefitinib or Chemotherapy for Non-Small-Cell Lung Cancer with Mutated EGFR. N Engl J Med 362:2380-2388.

30. Paez JG, Jänne PA, Lee JC, Tracy S, Greulich H, et al. (2004) EGFR mutations in lung cancer: correlation with clinical response to gefitinib therapy. Science 304: 1497-1500.

31. Kobayashi S, Boggon TJ, Dayaram T, Jänne PA, Kocher O, et al. (2005) EGFR mutation and resistance of non-small-cell lung cancer to gefitinib. N Engl J Med 352: 786-792.

32. Engelman JA, Zejnullahu K, Mitsudomi T, Song Y, Hyland C, et al. (2007) MET amplification leads to gefitinib resistance in lung cancer by activating ERBB3 signaling. Science 316: 1039-1043.

33. Sergina NV, Rausch M, Wang D, Blair J, Hann B, et al. (2007) Escape from HER-family tyrosine kinase inhibitor therapy by the kinase-inactive HER3. Nature 445: 437-441.

34. Yoshimura N, Kudoh S, Kimura T, Mitsuoka S, Matsuura K, et al. (2006) EKB-569, a new irreversible epidermal growth factor receptor tyrosine kinase inhibitor, with clinical activity in patients with non-small cell lung cancer with acquired resistance to gefitinib. Lung Cancer 51: 363-368. 